Artikel Penilitian

\title{
Sistem Pendukung Keputusan Pemilihan SMA Negeri Terfavorit Kota Pematangsiantar Menggunakan Metode MOORA
}

\author{
Muhammad Ilham, Iin Parlina, Arif Maulana, Ega Khairunnia Lubis, Sufiana Indah Sari
}

AMIK TUNAS BANGSA, Jalan Jendral Sudirman Blok A-B No 1/2/3, Pematangsiantar, Sumatera Utara , Indonesia

\section{KEYWORDS}

Five words maximum, comma separated

\section{CORRESPONDENCE}

Phone: 0852-6077-7474

E-mail: ilhamharigost@gmail.com

\section{PENDAHULUAN}

Kota Pematangsiantar merupakan kota tebesar kedua di Provinsi Sumatera Utara, dengan letak wilayah strategis yang dilintasi Jalan Raya Lintas Sumatera. Kota ini memiliki luas wilayah 79, $97 \mathrm{~km}^{2}$, jumlah penduduk sebanyak 251.516 jiwa (2017), dan jumlah SMA Negeri sebanyak 6 sekolah.

Sekolah Menengah Atas (SMA) adalah jenjang pendidikan menengah pada pendidikan formal di Indonesia setelah lulus Sekolah Lanjutan Tingkat Pertama (SLTP) sederajat. Sekolah Menengah Atas ditempuh dalam waktu 3 tahun, mulai dari kelas 10 sampai kelas 12. Sebagai kota besar dan memiliki cukup banyak sekolah, Pematangsiantar memiliki tantangan dalam menentukan Sekolah Menengah Atas yang berkualitas, untuk membantu para siswa lulusan SLTP untuk melanjutkan jenjang pendidikannya dan agar bisa dijadikan kiblat pendidikan di kota Pematangsiantar.
Decision Support System is a system that can be used in making decisions wisely there are quite a number of public high schools in the city. This study aims to help determine including School Accreditation, Student Graduation Level, Student Number, Schoo the selection of favorite public high schools is the Multi-Objective Optimization On The Basic

Sistem Pendukung Keputusan adalah sistem yang bisa digunakan dalam mengambil keputusan dengan bijak. Kota Pematangsiantar memiliki kesulitan dalam menentukan SMA untuk membantu menentukan SMA Negeri terfavorit kota Pematangsiantar. Pemelihan Kelulusan Siswa, Jumlah Siswa, Prestasi Sekolah dan Tenaga Pendidik. Metode yang adalah metode Multi-Objective Optimization On The Basic Of Ratio Analysist (MOORA). Hasil akhir yang diperoleh dari penelitian ini adalah perangkingan SMA Negeri Kota Pematangsiantar.

Dalam menentukan pilihan SMA yang tepat menjadi tantangan bagi siswa yang akan melanjutkan pendidikan dari tingkat SLTP khususnya SMA yang berstatus negeri. Karena dengan pilihan SMA yang tepat akan mempengaruhi pembelajaran yang didapat siswa.

Sistem Pendukung Keputusan (SPK) adalah salah satu cara mengorganisir informasi yang dimaksudkan untuk digunakan dalam membuat keputusan. Menyadari betapa pentingnya dalam menentukan SMA negeri yang tepat, maka perlu dibuatkan sistem pendukung keputusan yang dapat membantu siswa-siswi lulusan Sekolah Lanjutan Tingkat Pertama (SLTP) dalam menentukan SMA negeri terbaik dan terfavorit di kota Pematangsiantar. 


\section{TINJAUAN PUSTAKA}

\section{Sistem Pendukung Keputusan}

Sistem Pendukung Keputusan (SPK) adalah salah satu cara mengorganisir informasi yang dimaksudkan untuk digunakan dalam membuat keputusan. Ada yang mendefinisikan bahwa sistem pendukung keputusan merupakan suatu pendekatan untuk mendukung pengambilan keputusan. Sistem pendukung keputusan menggunakan data, memberikan antarmuka pengguna yang mudah dan dapat menggabungkan pemikiran pengambil keputusan[1]. Decision suport System (Sistem Pendukung Keputusan) merupakan sistem informasi pada level manajemen dari suatu organisasi yang mengkombinasikan data dan model analisis canggih atau peralatan data analisis untuk mendukung pengambilan keputusan keputusan yang semi terstruktur dan tidak terstruktur. Sistem pendukung keputusan pertama kali dikenalkan pada awal tahun 1970 oleh Michael S. Scott dengan istilah Management Decision System yang merupakan suatu sistem berbasis komputer yang membantu pengambilan keputusan dengan memanfaatkan data dan model - model untuk menyelesaikan masalah - masalah yang tidak terstruktur[2]

Sebuah keputusan dapat didefinisikan sebagai sebuah pilihan yang telah diambil dari dua atau beberapa alternatif yang tersedia. Setiap orang harus membuat banyak keputusan setiap harinya. Pilihan yang potensial dari sebuah keputusan terbentuk setelah mengetahui minimum objektif dan alternatif.

Sistem Pendukung Keputusan lebih ditujukan untuk mendukung manajemen dalam melakukan pekerjaan yang bersifat analitis dalam situasi yang kurang terstruktur dan dengan kriteria yang kurang jelas. SPK tidak dimaksudkan untuk mengotomatisasikan pengambilan keputusan tetapi memberikan perangkat interaktif yang memungkinkan pengambil keputusan untuk melakukan berbagai analisis menggunakan model- model yang tersedia.

\section{METODE}

\section{MOORA}

Metode MOORA adalah metode yang diperkenalkan oleh Braurers dan Zavadkas (2006). Metodeyang relatif baru ini digunakan oleh Braurers (2003) dalam suatu pengambilan keputusan multi kriteria. Metode MOORA memiliki tingkat fleksibilitas dan kemudahan untuk dipahami dalam memisahkan subjektif dari suatu proses evaluasi ke dalam kriteria bobot keputusan dengan beberapa atribut pengambilan keputusan [3]. Metode MOORA mudah dipahami dan fleksibel dalam memisahkan objek hingga proses evaluasi kriteria bobot keputusan. Metode MOORA juga memiliki tingkat selektifitas yang baik karena dapat menentukan tujuan dan kriteria yang bertentangan, yaitu kriteria yang bernilai menguntungkan (Benefit) atau yang tidak menguntungkan (Cost) [4].

Metode MOORA terdiri dari 4 langkah utama [5] sebagai berikut:

1. Penentuan nilai matrik keputusan

Menentukan Tujuan untuk mengindentifikasi atribut evaluasi yang bersangkutan

\section{$\mathrm{X}=[x 11 \times 12 \times 1 n \times 21 \times 22 \times 2 n \times 31 \times 32 \times 3 n]$}

2. Normalisasi matriks

Breaures (2008) menyimpulkan bahwa untuk penyebut, pilihan terbaik adalah akar kuadrat dari jumlah kuadrat dan setiap alternatif peratribut.

$\mathrm{X} * \mathrm{ij}=\mathrm{Xij} / \sqrt{ }[\Sigma x i j 2] m i=1$.

Untuk $\mathrm{j}=12 \ldots \mathrm{m}$.

\section{Mengoptimalkan Atribut}

Untuk optimasi Multiobjektif, ukuran yang dinormalisasi ditambahkan dalam kasus maksimasi (untuk atribut yang menguntungkan) dan dikurangi dalam kasus minimasi (untuk atribut yang tidak menguntungkan).

$\mathrm{Yi}=\Sigma-\Sigma x i j x n j=g+1 g j=1$

Dimana $\mathrm{G}$ adalah jumlah atribut yang akan dimaksimalkan, (ng) adalah jumlah atribut yang akan diminimalkan, dan yi adalah nilai penilaian yang telah dinormalisasikan dari altenatif 1 terhadap semua atribut.

Saat atribut bobot dioertimbangkan, persamaan 3 menjadi sebagai berikut:

$\mathrm{Yi}=\Sigma W g j=1 \mathrm{j} \mathrm{X} * \mathrm{I} \mathrm{j}-\Sigma W n j=g+1 \mathrm{j} W i j *$.

$\mathrm{Wj}$ adalah bobot dari Jth atribut, yang dapat ditentukan dengan menerapkan applying analtic hieararchy process (AHP) atau metode entrophy.

\section{Perangkingan nilai Yi}

Nilai Yi bisa positif atau negatif tergantung dari total maksimal dan minimal dalam matriks keputusan. Sebuah urutan peringkat dan Yi menujukan pilihan terakhir. Dengan demikian alternatif terbaik memiliki nilai Yi tertinggi, sedangkan alternatif terburuk memiliki nilai yang rendah.

\section{PEMBAHASAN}

Pada pembahasan berikut peneliti menyelesaikan permasalahan yang dihadapi kota Pematangsiantar dalam menentukan SMA Negeri terfavorit dengan menggunakan MOORA dalam perhitungannya. Proses - proses yang dilakukan pada metode Multi-Objective Optimization On The Basic Of Ratio Analysist (MOORA) sebagai berikut:

Tabel 1. Data Alternatif

\begin{tabular}{|l|l|}
\hline Alternatif & Keterangan \\
\hline S1 & SMA N 1 \\
\hline S2 & SMA N 2 \\
\hline S3 & SMA N 3 \\
\hline S4 & SMA N 4 \\
\hline S5 & SMA N 5 \\
\hline S6 & SMA N 6 \\
\hline
\end{tabular}


Tabel 2. Kriteria

\begin{tabular}{|l|l|l|l|}
\hline Kriteria & Keterangan & Bobot & Jenis \\
\hline C1 & Akreditasi & $25 \%$ & Benefit \\
\hline C2 & Tingkat Kelulusan & $15 \%$ & Benefit \\
\hline C3 & Jumlah Siswa & $15 \%$ & Benefit \\
\hline C4 & Prestasi & $25 \%$ & Benefit \\
\hline C5 & Tenaga Pendidik & $20 \%$ & Benefit \\
\hline
\end{tabular}

Tabel 3. Kriteria Akreditas dan Prestasi

\begin{tabular}{|l|l|}
\hline Akreditas / Prestasi & Bobot \\
\hline Sangat Baik & 5 \\
\hline Baik & 4 \\
\hline Cukup Baik & 3 \\
\hline Kurang Baik & 2 \\
\hline
\end{tabular}

Tabel 4. Kriteria Tingkat Kelulusan

\begin{tabular}{|l|l|}
\hline Keterangan & Bobot \\
\hline Lulus $100 \%$ & 5 \\
\hline Tidak Lulus $(<100 \%)$ & 0 \\
\hline
\end{tabular}

Tabel 5. Perangkingan Kriteria Jumlah Siswa

\begin{tabular}{|l|l|l|}
\hline Jumlah & Jangkauan & Bobot \\
\hline Sangat Banyak & $>1100$ & 5 \\
\hline Banyak & $901-1100$ & 4 \\
\hline Cukup Banyak & $701-900$ & 3 \\
\hline Sedikit & $0-700$ & 0 \\
\hline
\end{tabular}

Tabel 6. Kriteria Tenaga Pendidik

\begin{tabular}{|l|l|}
\hline Tenaga Pendidik & Bobot \\
\hline Sangat Kompeten & 5 \\
\hline Kompeten & 4 \\
\hline Cukup Kompeten & 3 \\
\hline
\end{tabular}

Tabel 7. Pemberian Nilai Setiap Penelitian

\begin{tabular}{|l|l|l|l|l|l|}
\hline Alternatif & C1 & C2 & C3 & C4 & C5 \\
\hline \multirow{2}{*}{ S1 } & Sangat & Lulus & Sangat & Cukup & \\
& Baik & $100 \%$ & Banyak & Baik & Kompeten \\
\hline \multirow{3}{*}{ S2 } & Sangat & Lulus & Sangat & Sangat & Sangat \\
S3 & Baik & $100 \%$ & Banyak & Baik & Kompeten \\
\hline & Sangat & Lulus & Sangat & & Cukup \\
S4n & Sangat & Lulus & Sangat & & Kompeten \\
\hline \multirow{3}{*}{ S5 } & Baik & $100 \%$ & Banyak & Baik & Kompeten \\
\hline & Baik & Lulus & & Cukup & Cukup \\
S6 & & Lulus & & Kompeten \\
\hline
\end{tabular}

Adapun diperoleh perubahan nilai setiap alternatif sebagai berikut
Tabel 8. Perubahan Nilai Setiap Alternatif

\begin{tabular}{|l|l|l|l|l|l|}
\hline Alternatif & C1 & C2 & C3 & C4 & C5 \\
\hline S1 & 5 & 5 & 5 & 3 & 4 \\
\hline S2 & 5 & 5 & 5 & 5 & 5 \\
\hline S3 & 5 & 5 & 5 & 4 & 4 \\
\hline S4 & 5 & 5 & 5 & 4 & 5 \\
\hline S5 & 4 & 5 & 4 & 3 & 3 \\
\hline S6 & 4 & 5 & 4 & 2 & 3 \\
\hline
\end{tabular}

Berdasarkan data diatas dapat dibuat matriks keputusan sebagai berikut:

Tabel 9. Matriks Keputusan

\begin{tabular}{|l|l|l|l|l|}
\hline 5 & 5 & 5 & 3 & 4 \\
\hline 5 & 5 & 5 & 5 & 5 \\
\hline 5 & 5 & 5 & 4 & 4 \\
\hline 5 & 5 & 5 & 4 & 5 \\
\hline 4 & 5 & 4 & 3 & 3 \\
\hline 4 & 5 & 4 & 2 & 3 \\
\hline
\end{tabular}

C1

$=\sqrt{5^{2}+5^{2}+5^{2}+5^{2}+4^{2}+4^{2}}=11,489$

$\mathrm{S}_{11} \quad=5 / 11,489=0,4352$

$\mathrm{S}_{21} \quad=5 / 11,489=0,4352$

$\mathrm{S}_{31} \quad=5 / 11,489=0,4352$

$\mathrm{S}_{41} \quad=5 / 11,489=0,4352$

$\mathrm{S}_{51} \quad=4 / 11,489=0,34816$

$\mathrm{S}_{61} \quad=4 / 11,489=0,34816$

$\mathrm{C} 2$

$=\sqrt{5^{2}+5^{2}+5^{2}+5^{2}+5^{2}+5^{2}}=12,247$

$=5 / 12,247=0,408263$

$=5 / 12,247=0,408263$

$=5 / 12,247=0,408263$

$=5 / 12,247=0,408263$

$=5 / 12,247=0,408263$

$=5 / 12,247=0,408263$

$=\sqrt{5^{2}+5^{2}+5^{2}+5^{2}+4^{2}+4^{2}}=11,489$

$=5 / 11,489=0,4352$

$=5 / 11,489=0,4352$

$=5 / 11,489=0,4352$

$=5 / 11,489=0,4352$

$=4 / 11,489=0,34816$

$=4 / 11,489=0,34816$

$=\sqrt{3^{2}+5^{2}+4^{2}+4^{2}+3^{2}+2^{2}}=8,888$

$=3 / 8,888=0,33753$

$=5 / 8,888=0,56256$

$=4 / 8,888=0,45005$

$=4 / 8,888=0,45005$

$=3 / 8,888=0,33753$

$=2 / 8,888=0,22503$

$=\sqrt{4^{2}+5^{2}+4^{2}+5^{2}+3^{2}+3^{2}}=10$

$=4 / 10=0,4$

$=5 / 10=0,5$

$=4 / 10=0,4$ 


$$
\begin{array}{ll}
\mathrm{S}_{45} & =5 / 10=0,5 \\
\mathrm{~S}_{55} & =3 / 10=0,3 \\
\mathrm{~S}_{65} & =3 / 10=0,3
\end{array}
$$

Maka dapat dilihat normalisasi matriks sebagai berikut:

Tabel 10. Normalisasi Matriks

\begin{tabular}{|l|l|l|l|l|}
\hline 0,4352 & 0,408623 & 0,4352 & 0,33753 & 0,4 \\
\hline 0,4352 & 0,408623 & 0,4352 & 0,56256 & 0,5 \\
\hline 0,4352 & 0,408623 & 0,4352 & 0,45005 & 0,4 \\
\hline 0,4352 & 0,408623 & 0,4352 & 0,45005 & 0,5 \\
\hline 0,34816 & 0,408623 & 0,34816 & 0,33753 & 0,3 \\
\hline 0,34816 & 0,408623 & 0,34816 & 0,22502 & 0,3 \\
\hline
\end{tabular}

Selanjutnya menghitung matriks normalisasi terbobot:

$$
\begin{aligned}
& \mathrm{C} 1=\mathrm{S}_{11} \quad=25 \% \times 0,4352=0,1088 \\
& \mathrm{~S}_{21} \quad=25 \% \times 0,4352=0,1088 \\
& \mathrm{~S}_{31} \quad=25 \% \times 0,4352=0,1088 \\
& \mathrm{~S}_{41} \quad=25 \% \times 0,4352=0,1088 \\
& \mathrm{~S}_{51} \quad=25 \% \times 0,34816=0,08704 \\
& \mathrm{~S}_{61} \quad=25 \% \times 0,34816=0,08704 \\
& \mathrm{C} 2=\mathrm{S}_{12}=15 \% \times 0,408623=0,06129345 \\
& \mathrm{~S}_{22} \quad=15 \% \times 0,408623=0,06129345 \\
& \mathrm{~S}_{32} \quad=15 \% \times 0,408623=0,06129345 \\
& \mathrm{~S}_{42} \quad=15 \% \times 0,408623=0,06129345 \\
& \mathrm{~S}_{52} \quad=15 \% \times 0,408623=0,06129345 \\
& \mathrm{~S}_{62} \quad=15 \% \times 0,408623=0,06129345 \\
& \mathrm{C} 3=\mathrm{S}_{13}=15 \% \times 0,4352=0,06528 \\
& \mathrm{~S}_{23} \quad=15 \% \times 0,4352=0,06528 \\
& \mathrm{~S}_{33} \quad=15 \% \times 0,4352=0,06528 \\
& \mathrm{~S}_{43} \quad=15 \% \times 0,4352=0,06528 \\
& \mathrm{~S}_{53} \quad=15 \% \times 0,34816=0,052224 \\
& \mathrm{~S}_{63} \quad=15 \% \times 0,34816=0,052224 \\
& \mathrm{C} 4=\mathrm{S}_{14} \quad=25 \% \times 0,33753=0,0843825 \\
& \mathrm{~S}_{24} \quad=25 \% \times 0,56256=0,14064 \\
& \mathrm{~S}_{34} \quad=25 \% \times 0,45005=0,1125125 \\
& \mathrm{~S}_{44} \quad=25 \% \times 0,45005=0,1125125 \\
& \mathrm{~S}_{54} \quad=25 \% \times 0,33753=0,0843825 \\
& \mathrm{~S}_{64} \quad=25 \% \times 0,22502=0,056255 \\
& \mathrm{C} 5=\quad \mathrm{S}_{15} \quad=20 \% \times 0,4=0,08 \\
& \mathrm{~S}_{25} \quad=20 \% \times 0,5=0,1 \\
& \mathrm{~S}_{35} \quad=20 \% \times 0,4=0,08 \\
& \mathrm{~S}_{45} \quad=20 \% \times 0,5=0,1 \\
& \mathrm{~S}_{55}=20 \% \times 0,3=0,06 \\
& \mathrm{~S}_{65}=20 \% \times 0,3=0,06
\end{aligned}
$$

Maka hasilnya dapat dilihat pada matriks berikut

Tabel 11. Matriks normalisasi terbobot

\begin{tabular}{|l|l|l|l|l|}
\hline 0,1088 & 0,06129345 & 0,06528 & 0,0843825 & 0,08 \\
\hline 0,1088 & 0,06129345 & 0,06528 & 0,14064 & 0,1 \\
\hline 0,1088 & 0,06129345 & 0,06528 & 0,1125125 & 0,08 \\
\hline 0,1088 & 0,06129345 & 0,06528 & 0,1125125 & 0,1 \\
\hline
\end{tabular}

\begin{tabular}{|l|l|l|l|l|}
0,08704 & 0,06129345 & 0,052224 & 0,0843825 & 0,06 \\
\hline 0,08704 & 0,06129345 & 0,052224 & 0,056255 & 0,06 \\
\hline
\end{tabular}

Selanjutnya pencarian nilai Yi sebagai berikut:

Tabel 12. Pencarian Nilai Yi

\begin{tabular}{|l|l|l|l|}
\hline $\begin{array}{l}\text { Alternati } \\
\mathrm{f}\end{array}$ & $\begin{array}{l}\text { Max } \\
\mathrm{C} 1+\mathrm{C} 2+\mathrm{C} 3+\mathrm{C} 4+\mathrm{C} 5+\mathrm{C} 6)\end{array}$ & $\begin{array}{l}\text { Min } \\
=0\end{array}$ & $\begin{array}{l}\text { Yi }=\text { Max- } \\
\text { Min }\end{array}$ \\
\hline S1 & 0,39975595 & 0 & 0,39975595 \\
\hline S2 & 0,47601345 & 0 & 0,47601345 \\
\hline S3 & 0,42788595 & 0 & 0,42788595 \\
\hline S4 & 0,44788595 & 0 & 0,44788595 \\
\hline S5 & 0,34493995 & 0 & 0,34493995 \\
\hline S6 & 0,31681245 & 0 & 0,31681245 \\
\hline
\end{tabular}

Adapun hasil perangkingan sebagai berikut:

Tabel 13. Perangkingan Nilai Yi

\begin{tabular}{|l|l|l|}
\hline Alternatif & Yi & Rangking \\
\hline S1 & 0,39975595 & 4 \\
\hline S2 & 0,47601345 & 1 \\
\hline S3 & 0,42788595 & 3 \\
\hline S4 & 0,44788595 & 2 \\
\hline S5 & 0,34493995 & 5 \\
\hline S6 & 0,31681245 & 6 \\
\hline
\end{tabular}

Dari proses tersebut maka dapat diputuskan bahwa alternatif S2 atau SMA Negeri 2 merupakan SMA terfavorit di Pematangsiantar.

\section{KESIMPULAN}

Berdasarkan penelitan yang telah dijelaskan, sehingga dapat ditarik kesimpulan yaitu Aplikasi SPK dengan menggunakan metode MOORA maka perangkingan SMA Negeri terfavorit adalah sebagai berikut:
1. SMA Negeri 2
2. SMA Negeri 4
3. SMA Negeri 3
4. SMA Negeri 1
5. SMA Negeri 5
6. SMA Negeri 6

\section{DAFTAR PUSTAKA}

[1] I. Parlina, "Analisis Sistem Pendukung Keputusan Pemilihan Anggota Paskibraka Menggunakan Metode Electre Analysis Of Decision Support System For National Flag Hoisting Troop Membership Using Electre Method," JITE (Journal Informatics Telecommun. Eng., vol. 2, no. 1, pp. 39-47, 2018.

[2] S. Manurung, "SISTEM PENDUKUNG KEPUTUSAN PEMILIHAN GURU DAN PEGAWAI TERBAIK MENGGUNAKAN METODE MOORA," J. SIMETRIS, vol. 9, no. 1, pp. 701-706, 2018. 
[3] M. Ashari and F. Mintarsih, "Aplikasi Pemilihan Bibit Budidaya Ikan Air Tawar dengan Metode MOORA Entropy," J. Sist. Inf., vol. 5341, no. October, 2017.

[4] S. Wardani, I. Parlina, and A. Revi, "ANALISIS PERHITUNGAN METODE MOORA DALAM PEMILIHAN SUPPLIER BAHAN BANGUNAN DI TOKO MEGAH GRACINDO JAYA InfoTekJar ( Jurnal Nasional Informatika dan Teknologi Jaringan )," (Jurnal Nas. Inform. dan Teknol. Jaringan), vol. Vpl 3, No, pp. 95-99, 2018.

[5] A. Kusuma, A. Nasution, R. Safarti, R. K. Hondro, and E. Buulolo, "Sistem Pendukung Keputusan Pemilihan Siswa / I Teladan Dengan Menggunakan Metode Multi-Objective Optimization on The Basis of Ratio Sistem Pendukung Keputusan Pemilihan Siswa / I Teladan Dengan Menggunakan Metode MultiObjective Optimization on The Basis," J. Ris. Komput., vol. Vol. 5 No., no. April, pp. 114-119, 2018. 